\title{
Geometrical Stepper-Guided Navigation System for ProACT Implant under Transrectal Ultrasound Control: Preliminary Data
}

\author{
Simone Crivellaro ${ }^{a}$ Lorenzo Tosco $^{a}$ Anna Palazzetti ${ }^{a}$ Maria Abbinante ${ }^{a}$ \\ Guillermo Martinez $^{\mathrm{a}}$ Ervin Kocjancic $^{\mathrm{b}}$ Bruno Frea $^{\mathrm{a}}$

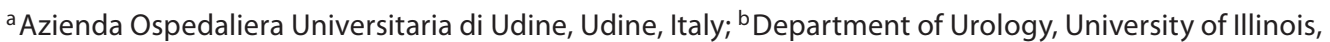 \\ Chicago, III., USA
}

Key Words

Incontinence $\cdot$ Male $\cdot$ Surgery

\begin{abstract}
Purpose: To describe a new geometrical stepper-guided navigation system for positioning ProACT ${ }^{\circledR}$. Methods: The sizing of the stepper-guided navigation system was calculated using the distance from the ideal position of the device to anatomic referral points previously measured by ultrasound. The trocar and subsequently the device were maneuvered to the ideal position in accordance with the navigation system. Measurements: Treatment efficacy was evaluated with daily pad count, 1-hour pad test, Incontinence Quality of Life questionnaire (IQoL), visual analog scale and overall impression. Complications, balloon volume and number of adjustments were reported at 1, 3, 6 and 12 months follow-up visits. $\boldsymbol{R e}$ sults: Mean follow-up was 12 (range 3-19) months. Daily pad count showed 30 patients (71\%) dry and 9 patients $(21 \%) \mathrm{im}$ proved. 1 hour pad test showed 28 patients were dry (66\%) and 11 patients improved (26\%). IQoL increased from an average of 35.3 to 80 . Average visual analog scale score was 8 . Complications requiring device removal occurred in 3 patients (7\%). Mean balloon volume was $3.1 \mathrm{ml}$. Conclusions: The stepper-guided navigation system to implant ProACT is feasible and extremely reproducible making this procedure more standardized.

Copyright $\odot 2012$ S. Karger AG, Basel
\end{abstract}

\begin{tabular}{|c|c|}
\hline KARGER & $\begin{array}{l}\text { (C) } 2012 \text { S. Karger AG, Basel } \\
0042-1138 / 12 / 0894-0473 \$ 38.00 / 0\end{array}$ \\
\hline $\begin{array}{l}\text { Fax +4161306 } 1234 \\
\text { E-Mail karger@karger.ch } \\
\text { www.karger.com }\end{array}$ & $\begin{array}{l}\text { Accessible online at: } \\
\text { www.karger.com/uin }\end{array}$ \\
\hline
\end{tabular}

\section{Introduction}

The incidence of postprostatectomy stress urinary incontinence varies in the literature between 0.8 and $87.0 \%$ [1-4], although in high-volume centers the reported rates are between 2 and $9 \%[5,6]$.

The Adjustable Continence Therapy (ProACT ${ }^{\circledR}$; Uromedica, Plymouth, Minn., USA) is a well-established surgical treatment for male stress urinary incontinence after prostate surgery. The implantation technique has been described using either fluoroscopic imaging [7-11] or transrectal ultrasound (TRUS) guidance [12]. Both techniques allow for identification of generic anatomic landmarks but no measurable and reproducible referral points for the implantation. For this reason we decided to use a special device called the 'stepper' (fig. 1) which would enable an easier placement freeing both hands for manipulation of the ProACT trocar during implantation and allow visualization of fixed referral points.

This study aims to evaluate the safety and the efficacy of using a geometrical stepper-guided navigation system for positioning ProACT under TRUS control.

Prof. Bruno Frea

Clinica Urologica, Azienda Ospedaliera Universitaria di Udine Piazzale S. Maria Misericordia 15

IT-33100 Udine (Italy)

Tel. +39 43255 2931, E-Mail crivellaro.simone@ aoud.sanita.fvg.it 


\section{Patients and Methods}

The ProACT System

The ProACT system consists of two silicone elastomer balloons designed to be placed on either side of the vesicourethral anastomosis in post radical prostatectomy patients. The devices are placed using a special trocar contained in a U-shaped sheath through a transperineal route above the perineal muscles. Each balloon is attached via a two lumen conduit to a titanium port buried in the anterior lateral aspect of the scrotum. One lumen contains a removable $15-\mathrm{cm}$ by $0.8-\mathrm{mm}$ push wire, while the other acts as a channel for balloon inflation. Postoperative adjustment of the balloon is facilitated by percutaneous injection of the port using a 23-gauge noncoring needle. The implant is available in 12 and $14 \mathrm{~cm}$ length and each balloon can be inflated up to $8 \mathrm{ml}$ over time if necessary.

\section{Patient Population}

After obtaining institutional review board approval, we operated on 42 consecutive patients (mean age: 65.2 years; range: $21-$ 80 ) with post radical prostatectomy and urodynamic proven intrinsic sphincter deficiency between April 2009 and October 2010. Flexible cystoscopy was performed in order to exclude urethral strictures. At baseline, all patients underwent urodynamic examination in accordance with the International Continence Society guidelines [13]. Patients with detrusor over-activity were excluded. Incontinence was evaluated using daily pad count (DPC), and categorized as mild (one or two DPC), moderate (three to five DPC), and severe (more than five DPC or condom use). Additionally a standardized 1-hour pad test was administered. The gram weight of urine loss was recorded and subdivided into three groups defined according to the grams of urine loss: mild ( $<10 \mathrm{~g})$, moderate $(>10,<50 \mathrm{~g})$, and severe $(>50 \mathrm{~g})[13]$.

All patients were assessed with the incontinence quality of life questionnaire (IQoL) validated by Wagner et al. [14]. Table 1 lists patient characteristics at baseline.

\section{Surgical Technique}

The patient is placed in the lithotomy position. A 14-Ch Foley catheter is inserted, and the bladder filled with $40-50 \mathrm{ml}$ of saline solution to clearly visualize the bladder neck with TRUS. The scrotum is held above the perineum with tape. The anal ring is isolated from the perineum with a drape. At this point a $7.5-\mathrm{MHz}$ biplanar probe is located on the stepper device (fig. 1) to implement the navigation system. Basically, the system is based on preoperative echographic measurement that reported on the skin and on the instrumentation allowing the operator to plan and perform an extremely precise implantation.

Optimal balloon placement is considered as being $5-10 \mathrm{~mm}$ distal to the bladder neck, $5-10 \mathrm{~mm}$ proximal to the perineal muscles and $2-5 \mathrm{~mm}$ lateral to the membranous urethra. Ideally, the balloons should be at 9 o'clock and 3 o'clock to create a triangular coaptation of the urethra between the two balloons and the pubic symphysis $[15,16]$. Distances from the ideal location of the balloon to the pubic symphysis, ischiopubic rami, urethra and probe in the transversal view (fig. 2) are measured and reported on the perineal skin (fig. 3). The distance from the ideal position of the balloon to the perineal skin (fig. 4) is measured in the longitudinal view and reported on a Chiba needle (fig. 5).

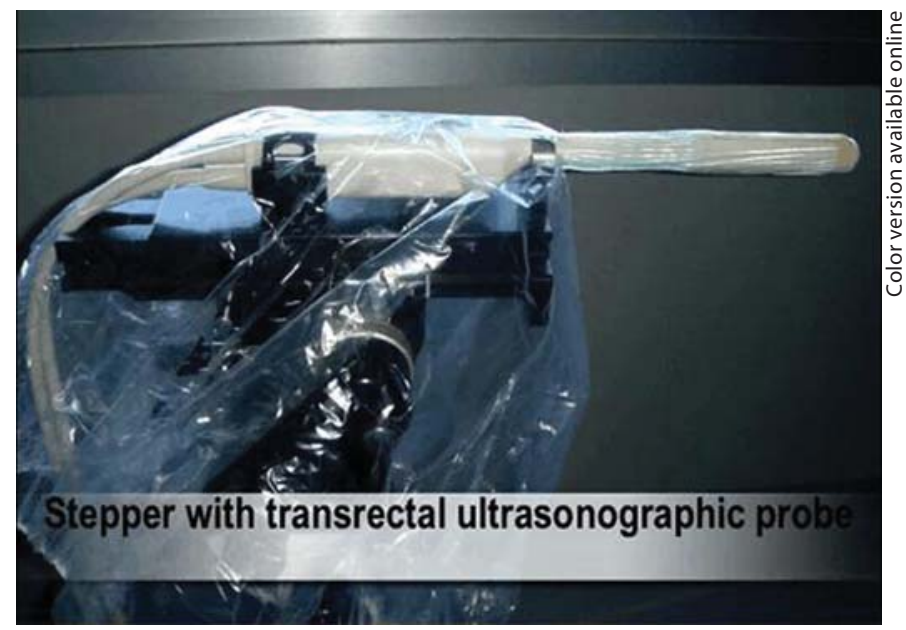

Fig. 1. Stepper with transrectal ultrasound probe in place.

Table 1. Population characteristics

\section{Patients}

Mean age, years

$65.2(21-80)$

Mean interval between RP and ProACT, months

$38(9-110)$

No. patients with previous adjuvant radiotherapy

Patients with previous anti-SUI surgery

Degree of incontinence (pad count), patients

Mild

10

Moderate

12

Severe

15

15

Degree of incontinence ( $1 \mathrm{~h}$ pad test), patients

Mild

Moderate 18

Severe 14

Mean VLPP, $\mathrm{cm} \mathrm{H}_{2} \mathrm{O}$

Mean MUCP, $\mathrm{cm} \mathrm{H}_{2} \mathrm{O}$

Mean PPD

$50(15-102)$

$40.8(6-80)$

Mean IQoL score

MUCP = Maximal urethral closure pressure; PPD = pads per day; $\mathrm{RP}=$ radical prostatectomy; VLPP = Valsalva leak point pressure. Figures in parentheses are ranges.

Two horizontal $0.5-$ to $1-\mathrm{cm}$ skin incisions are made at the premarked perineal entry point. A 20 -gauge Chiba needle is inserted through the skin incisions under biplanar TRUS guidance until the marker on the needle reaches the skin edge (fig. 6). The linear probe monitors advancement of the 20 -gauge Chiba needle towards the vesicourethral anastomosis, while the convex probe is used to monitor the lateral distance from the urethra (fig. 7). 


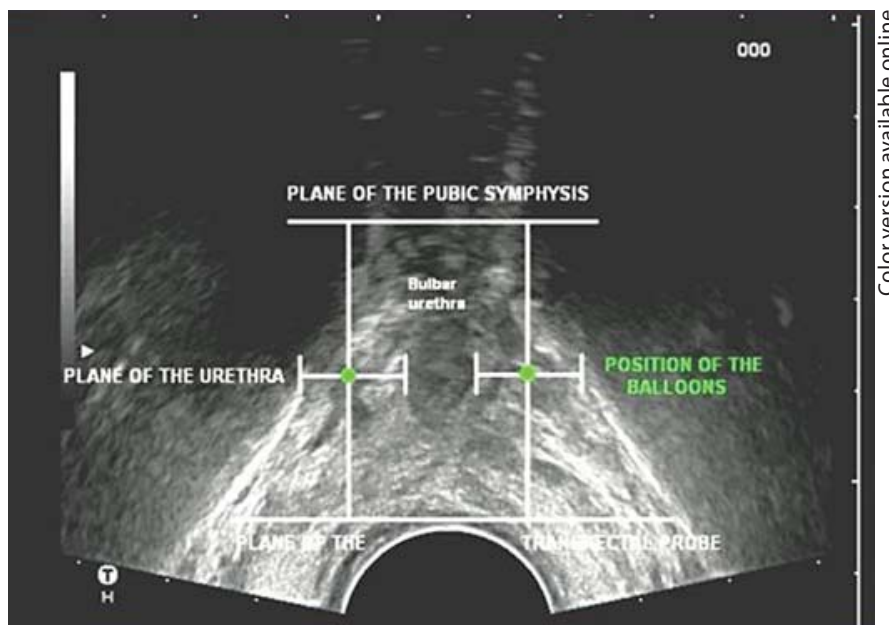

Fig. 2. Geometrical navigation system on transversal ultrasound view.

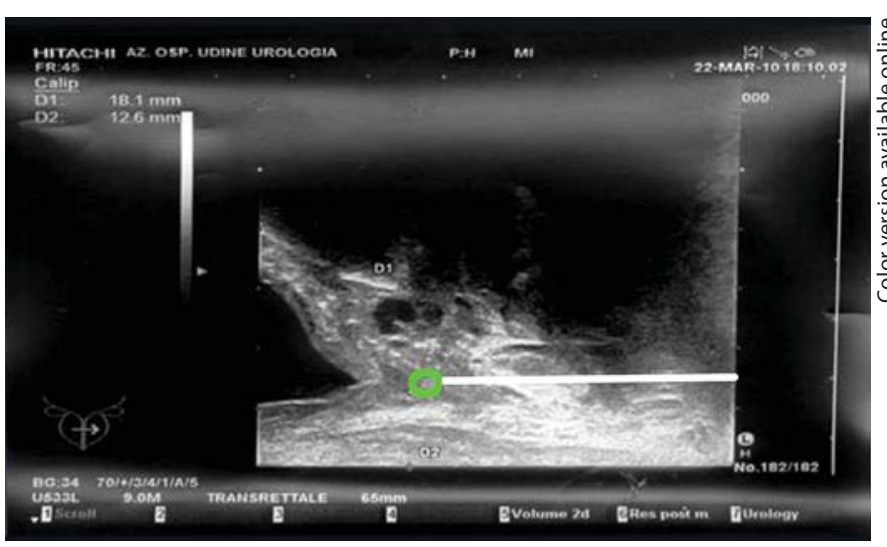

Fig. 4. Geometrical navigation system on longitudinal ultrasound view.

At this point hydrodissection is obtained using saline solution administered through the 20 -gauge Chiba needle laterally to the anastomosis, creating a space for the ProACT balloon.

The longitudinal distance between anastomosis and perineal skin edge measured on the Chiba needle is verified by TRUS and confirmed on the dedicated trocar contained within a U-shaped sheath (fig. 8). Under TRUS guidance, the trocar is inserted through the skin incision until the marker reaches the skin border (fig. 9). A twisting motion is employed to perforate the pelvic diaphragm and advance the trocar towards the hydrodissected scar tissue at the level of anastomosis. The position of the trocar and cannula is continuously confirmed by TRUS (fig. 10).

The trocar is removed, leaving the U-shaped sheath in place. During this maneuver the sheath is gently advanced about $0.5 \mathrm{~mm}$

A New Technique to Implant ProACT

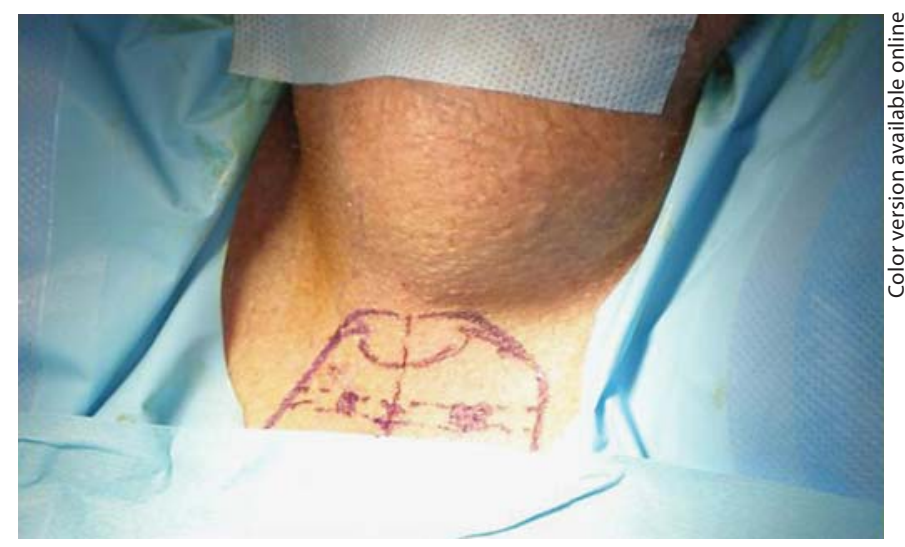

Fig. 3. Geometrical navigation system reported on the surgical field.

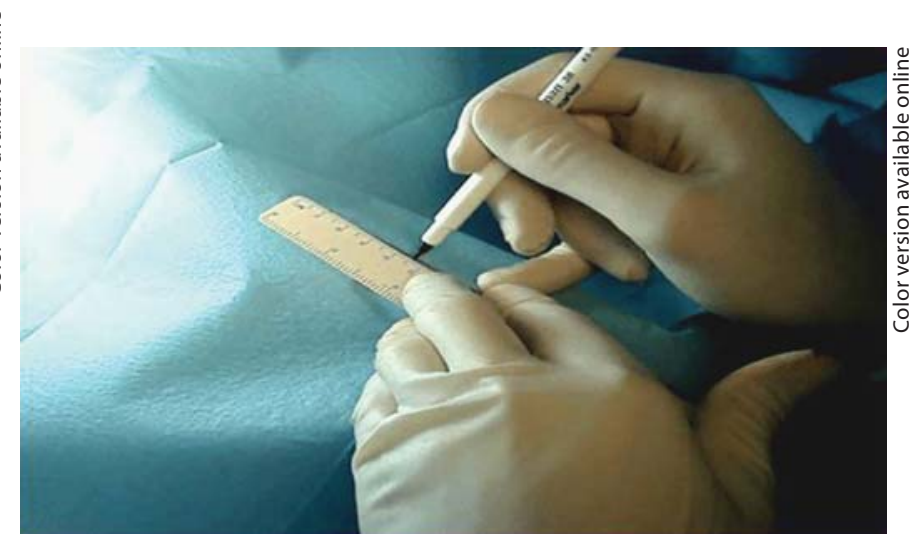

Fig. 5. Geometrical navigation system reported on the Chiba needle.

to occupy the space created by the trocar tip. The internal channel of the sheath is then lubricated using sterile gel. With the help of the push wire, the ProACT device is passed along the sheath into position at the anastomosis (fig. 11).

The sheath is withdrawn and the balloon is inflated with $1 \mathrm{ml}$ isotonic contrast solution via the titanium port. TRUS is used to confirm correct balloon placement (fig. 12).

The push wire is removed. Using a Kelly clamp, a subcutaneous parascrotal pocket is fashioned to allow placement of the conduit tube and titanium port. The procedure is repeated on the contralateral side. The incisions are cleaned with a gentamicin flush and closed in two layers with 4-0 resorbable sutures. The Foley catheter is maintained overnight. A 5-day oral prophylactic course of fluoroquinolonics was given to all patients. 


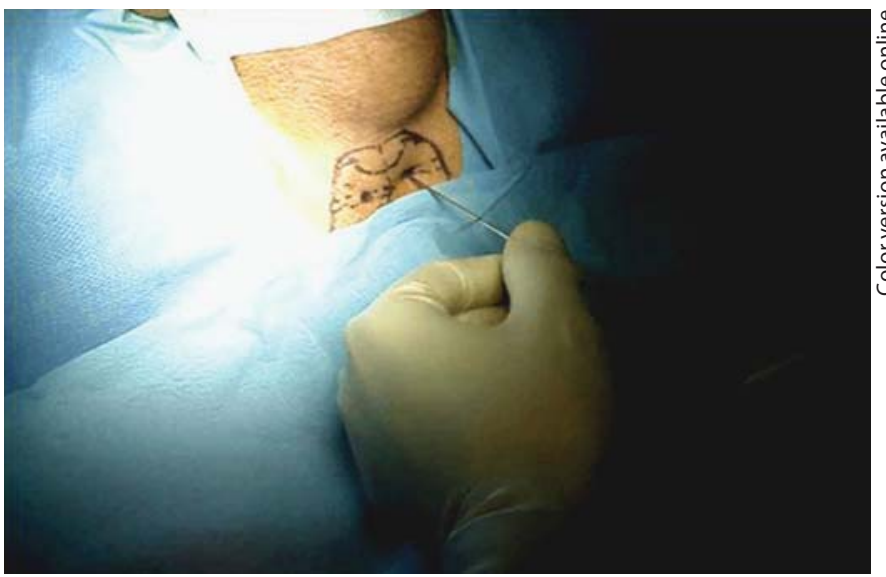

Fig. 6. Needle insertion according with the reported measurements.

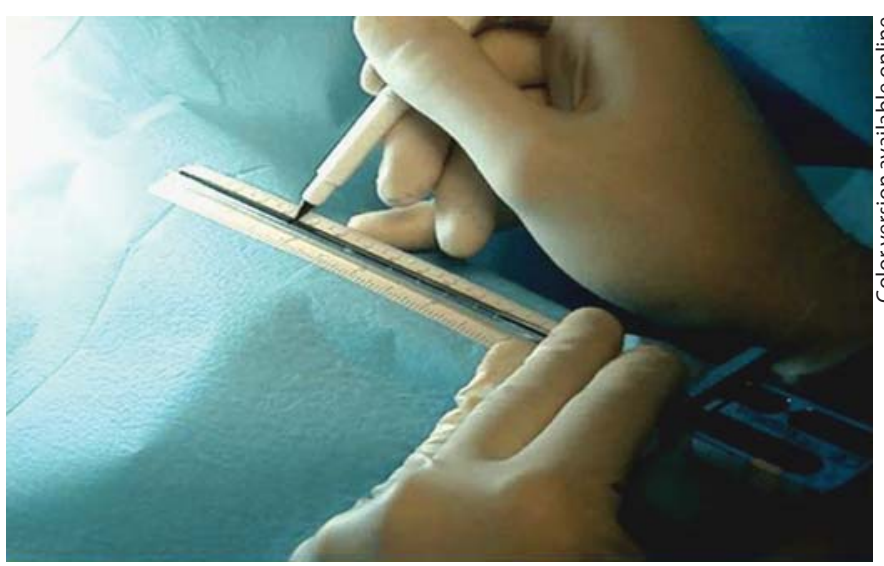

Fig. 8. Geometrical navigation system reported on the trocar.

\section{Follow-Up and Postoperative Adjustment}

After 30 days, the patient is evaluated according to the DPC. If complete continence has not been achieved, each balloon is filled with a further $1 \mathrm{ml}$ isotonic contrast solution $(0.5 \mathrm{ml}$ in previously irradiated patients). The procedure is performed through percutaneous access to the two titanium ports with a 23-gauge noncoring needle without the need for any anesthesia. The same patient evaluation and balloon adjustment are done every 30 days until continence or a maximum filling volume of $8 \mathrm{ml}$ is reached. If the system fails to achieve continence or a complication occurs, each balloon may be deflated and simply removed using local an-

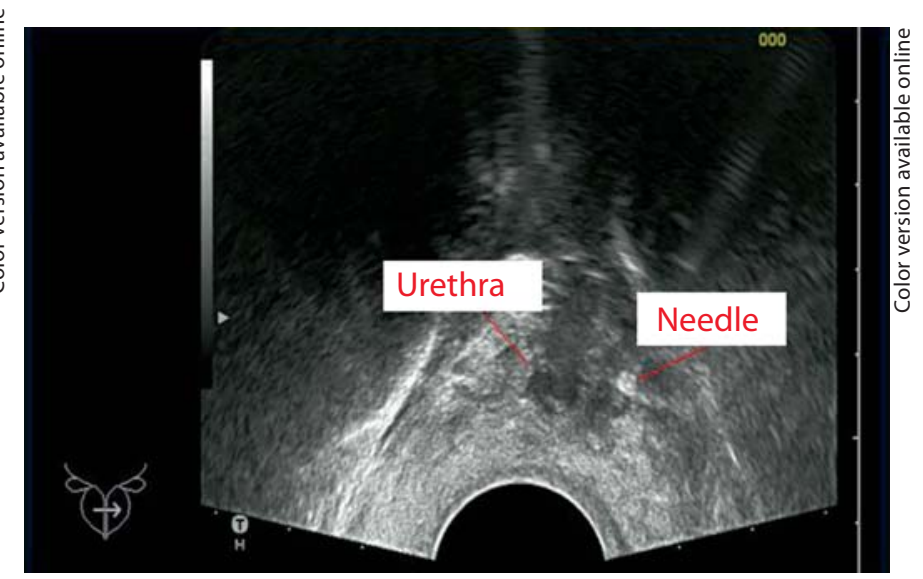

Fig. 7. Needle insertion controlled by ultrasound.

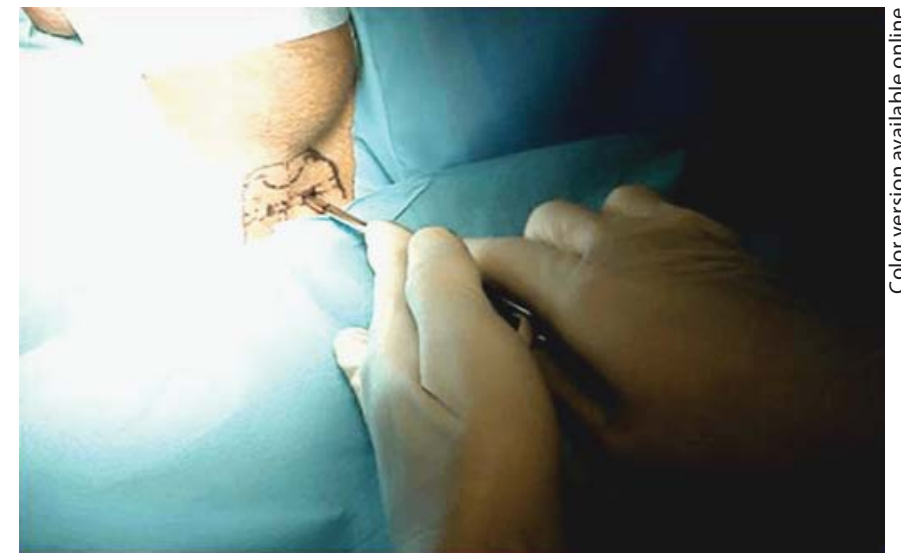

Fig. 9. Trocar insertion according with the reported measurements.

esthesia through a small skin incision in the area where the titanium port is located.

After balloon adjustments were completed, patients were assessed with the DPC (no or one safety pad was considered dry; $>50 \%$ reduction in number of pads was considered improved; $<50 \%$ reduction in number of pads was considered failure), $1 \mathrm{~h}$ pad test (dry $<5 \mathrm{~g}$ ), improved (grams reduced more than 50\%), and unchanged (grams reduced less than 50\%).

IQoL questionnaire, overall impression (dry, improved, unchanged), visual analog scale (0-10), perioperative data and adverse events were recorded for all patients. 


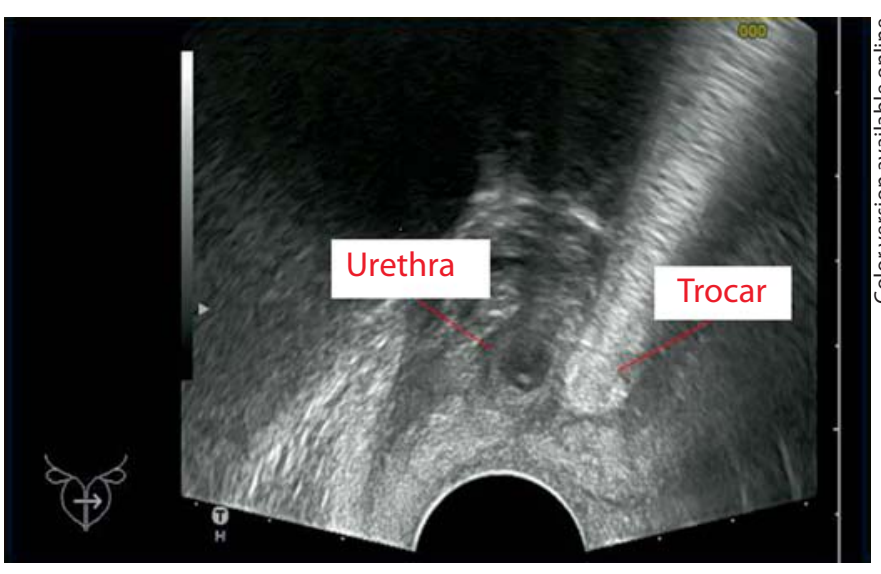

Fig. 10. Trocar insertion controlled by ultrasound.

\section{Results}

\section{Operative Results}

Mean time for ProACT implantation was $20 \mathrm{~min}$ (range: 12-35) using spinal anesthesia in all patients. Two 14-cm long devices were placed in all patients. Blood loss was unremarkable in all cases. No patients required postoperative analgesia. In all patients, the Foley catheter was removed the morning after the procedure before hospital discharge.

\section{Continence Outcome Data}

All 42 patients have completed balloon adjustments. The mean follow-up is 12 months (range: $3-19)$ ). The mean number of postoperative adjustments required was 2.6 (range: $0-10$ ). Five patients were dry with no adjustments at all. The mean balloon volume required was $3.2 \mathrm{ml}$ on the right and $3.1 \mathrm{ml}$ on the left (range: $1-8)$. Based on mean DPC, 30 patients were dry (71\%), 9 patients improved (21\%), and 3 patients failed treatment (8\%). According to the degree of incontinence, the dry rate in patients with mild, moderate, and severe incontinence was, respectively, $83 \%$ (10 of 12 patients), $73 \%$ (11 of 15 patients), and $60 \%$ (9 of 15 patients). Based on 1-hour pad test at the last follow-up visit 28 patients were dry (66\%), 11 patients improved (26\%), and 3 patients failed treatment (8\%). Mean IQoL score improved from 35.3 to 80 . Average visual analog scale score was 8 . Overall impression showed $70 \%$ dry and $20 \%$ Improved. The overall dry rate in nonirradiated and patients with no prior treatments was $85 \%$.

A New Technique to Implant ProACT
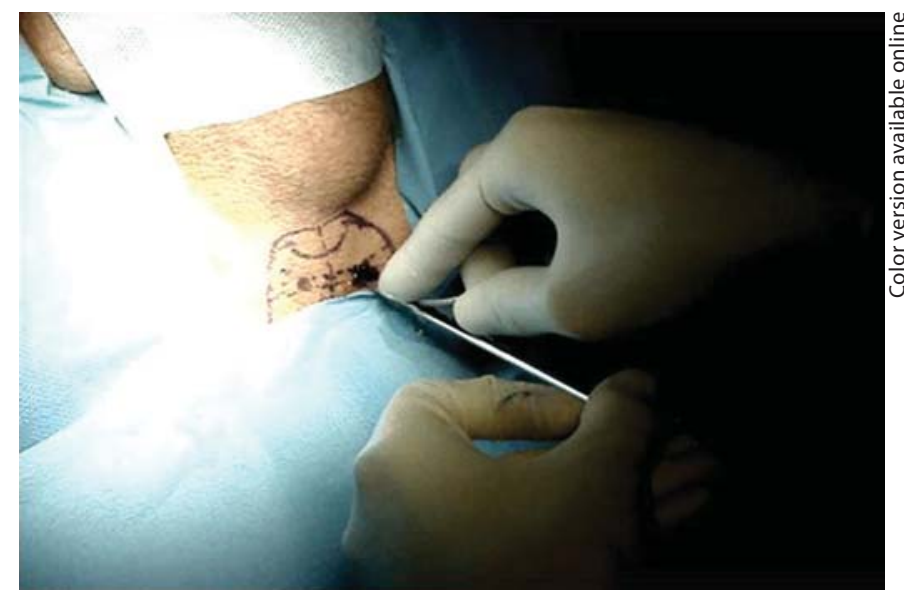

Fig. 11. ProACT inserted in the sheath.

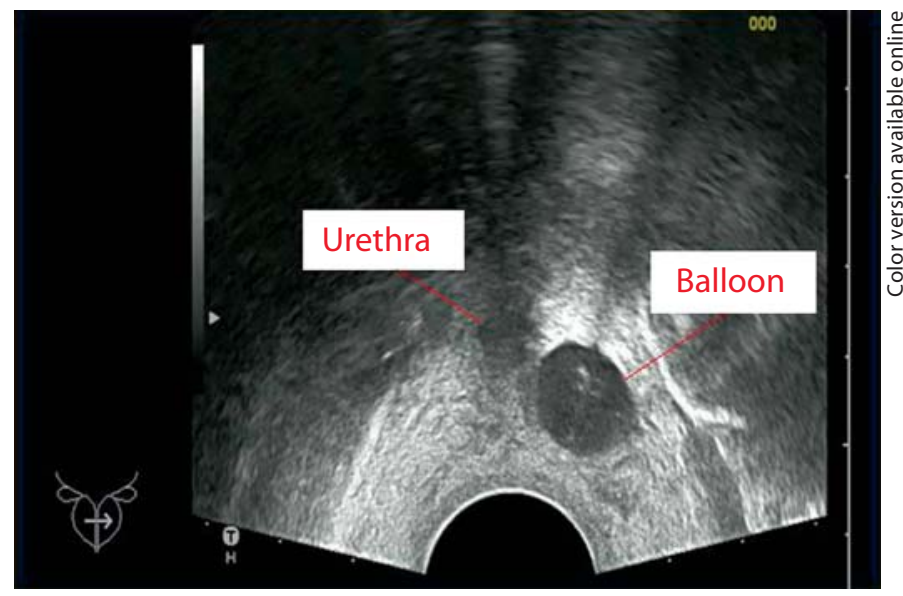

Fig. 12. ProACT in place.

\section{Perioperative Complications}

Intraoperative. One bladder perforation occurred and was immediately recognized by the leaking of saline through the U-shaped sheath and confirmed by ultrasound. The sheath was removed and the procedure was successfully repeated modifying the measurements of the trocar placement more laterally. An indwelling catheter was placed for 5 days with no further complications.

Early Postoperative. One device infection was observed 10 days after the procedure. The device was removed under local anesthesia with no further sequelae.

Urol Int 2012;89:473-479

477 
Late Postoperative. One unilateral balloon migration and one urethral erosion were recorded 3 and 6 months after surgery in previously irradiated patients. These complications were easily managed by balloon removal in the outpatient department using local anesthesia. The patient who had urethral erosion had an indwelling catheter for 15 days and a flexible cystoscopy confirmed complete urethral healing. One month after complete urethral healing had been confirmed, unilateral reimplantation was performed without further complications.

All the patients who had complications had been previously irradiated.

\section{Discussion}

In the treatment of postprostatectomy stress urinary incontinence, when conservative methods (such as pelvic floor muscle exercises) fail, several surgical treatments are available. The most popular, in order of increasing complexity, are ProACT, male slings and artificial urinary sphincter (AUS).

Many different male perineal slings are available at the moment. Published success rates range from 38 to $76 \%$ depending on the outcome measures used. The most common complications are infection and temporary urinary retention [17-19]. Less common complications include persistent urinary retention (3\% rate) and erosion of the sling into the urinary tract (2\% rate) [18]. Infection or erosion requires removal of the sling, during which the surgeon might encounter significant fibrosis.

Many urologists believe the AUS to be the gold standard for treatment of male stress urinary incontinence. Published success rates, generally reported as 'socially continent rates' of up to one pad per day, range from 58 to $88 \%[20,21]$. Common complications of an AUS include infection, erosion, and device malfunction [22].

The ProACT device was first developed in 2000 and has been reported extensively since that time [7-12, 15]. Regardless of the different techniques of implantation (under fluoroscopic or TRUS control) dry rates have been described around $62-67 \%$.

The introduction of the hand-guided ultrasound technique as Gregori et al. [16] decreased the intraoperative and early rates of complications $(3.7 \%$ compared with 7.8-12.8\%). Possibly, the previously suboptimal placement using fluoroscopic guidance necessitated higher balloon volumes and therefore increased the risk of early complications such as infection and migration. This technique also demonstrated a reduction in long-term postoperative (7.9\% compared with $11.0-27.4 \%)$ complications particularly urethral and or bladder erosion. The authors explain this decrease as a result of the more precise device placement with ultrasound guidance. The fact still remains that the average balloon filling in patients implanted by hand-guided ultrasound control $(4.2 \mathrm{ml})$ was comparable with that in other studies under fluoroscopy $(3.2-4.6 \mathrm{ml})$ and not lower as expected.

Our data show that the introduction of a geometrical stepper-guided navigation system to implant ProACT under TRUS control allowed us to reach the same continence rate as reported in the literature (70 vs. $62-67 \%$ ) with a lower intraoperative-early (4.7\% compared with $7.8-12.8 \%)$ and late complication rate (4.7\% compared with 11.0-27.4\%). Importantly, a lower mean balloon volume and number of adjustments (3.1 vs. $3.2-4.6 \mathrm{ml}$ and 2.6 vs. 3.1-4.3) could be achieved using this technique. We think that this will lead in the future to a lower incidence of later complications such as erosion or migration and is due to an even more precise device placement thanks to the stepper-guided navigation system.

In our opinion, this system represents an evolution of the regular hand-guided TRUS technique because it makes the operation more standardized and gives the ability to use both hands to manipulate the trocar, making the balloon placement safer and more precise.

Despite the limits of the present study (medium-term follow-up), our early outcome data are very encouraging with a low complication rate and a decreased number of postoperative adjustments required to reach continence.

As reported in other series, results were worse in patients with severe leakage and in patients previously irradiated or surgically treated for incontinence, who are also at higher risk of perioperative complications.

\section{Conclusions}

In conclusion, the use of geometrical stepper-guided navigation system for ProACT implantation under TRUS control is safe and reproducible. The results are at least comparable with published data on ProACT implantation using the original fluoroscopic or non-stepper-guided ultrasound technique with a slightly less complication rate. Of significance is that the more accurate balloon placement results in less volumetric requirement and therefore less postoperative adjustments in order to reach optimum continence. 


\section{References}

$\checkmark 1$ Augustin H, Pummer K, Daghofer F, Habermann H, Primus G, Hubmer G: Patient selfreporting questionnaire on urological morbidity and bother after radical retropubic prostatectomy. Eur Urol 2002;42:112-117.

-2 Burkhard FC, Kessler TM, Fleischmann A, Thalmann GN, Schumacher M, Studer UE: Nerve-sparing open radical retropubic prostatectomy - does it have an impact on urinary continence? J Urol 2006;176:189-195.

$\checkmark 3$ Penson DF, McLerran D, Feng Z, et al: Fiveyear urinary and sexual outcomes after radical prostatectomy: results from the prostate cancer outcomes study. J Urol 2005;173: 1701-1705.

$\checkmark 4$ Rudy DC, Woodside JR, Crawford ED: Urodynamic evaluation of incontinence in patients undergoing modified Campbell radical retropubic prostatectomy: a prospective study. J Urol 1984;132:708-712.

$\checkmark 5$ Hammerer P, Huland H: Urodynamic evaluation of changes in urinary control after radical retropubic prostatectomy. J Urol 1997; 157:233-236.

$\checkmark 6$ Walsh PC, Partin AW, Epstein JI: Cancer control and QoL following anatomical radical retropubic prostatectomy: results at 10 years. J Urol 1994;152:1831-1836.

7 Hubner WA, Schlarp OM: Treatment of incontinence after prostatectomy using a new minimally invasive device: adjustable continence therapy. BJU Int 2005;96:587-594.

$>8$ Trigo-Rocha F, Gomes CM, Pompeo AC, Lucon AM, Arap S: Prospective study evaluating efficacy and safety of adjustable continence therapy (ProACT) for post radical prostatectomy urinary incontinence. Urology 2006;67:965-969.
Kocjancic E, Crivellaro S, Ranzoni S, Bonvini D, Gontero P, Frea B: Adjustable continence therapy for the treatment of male stress urinary incontinence: a single-centre study. Scand J Urol Nephrol 2007;41:324328.

10 Lebret T, Cour F, Benchetrit J, et al: Treatment of postprostatectomy stress urinary incontinence using a minimally invasive adjustable continence balloon device, ProACT: results of a preliminary, multicenter, pilot study. Urology 2008;71:256-260.

11 Gilling PJ, Bell DF, Wilson LC, Westenberg AM, Reuther R, Fraundorfer MR: An adjustable continence therapy device for treating incontinence after prostatectomy: a minimum 2-year follow-up. BJU Int 2008;102 1426-1430.

12 Gregori A, Simonato A, Lissiani A, Scieri F, Rossi R, Gaboardi F: Transrectal ultrasound guided implantation of the ProACT adjustable continence therapy system in patients with post-radical prostatectomy stress urinary incontinence: a pilot study. J Urol 2006; 176:2109-2113.

13 Abrams P, Cardozo L, Fall M, et al: The standardisation of terminology in lower urinary tract function: report from the standardisation sub-committee of the International Continence Society. Urology 2003;61:37-49.

14 Wagner TH, Patrick DL, Bavendam TG, Martin ML, Buesching DP: Quality of life of persons with urinary incontinence: development of a new measure. Urology 1996;47:6771.
5 Giammò A, Bodo G, Castellano S, Borrè A, Carone R: Spiral multidetector computerized tomography evaluation of adjustable continence therapy implants. J Urol 2010; 183:1921-1926.

16 Gregori A, Romanò AL, Scieri F, Pietrantuono F, Incarbone GP, Salvaggio A, Granata A, Gaboardi F: Transrectal ultrasound-guided implantation of adjustable continence therapy (ProACT): surgical technique and clinical results after a mean follow-up of 2 years. Eur Urol 2010;57:430-436.

17 Rajpurkar AD, Onur R, Singla A: Patient satisfaction and clinical efficacy of the new perineal bone-anchored male sling. Eur Urol 2005; 47:237-242.

18 Fischer MC, Huckabay C, Nitti VW: The male perineal sling: assessment and prediction of outcome. J Urol 2007;177:1414-1418.

19 Rehder P, Gozzi C: Transobturator sling suspension for male urinary incontinence including post-radical prostatectomy. Eur Urol 2007;52:860-866.

20 Elliott DS, Barrett DM: Mayo Clinic longterm analysis of the functional durability of the AMS 800 artificial urinary sphincter: a review of 323 cases. J Urol 1998;159:12061208.

21 Raj GV, Peterson AC, Toh KL, Webster GD: Outcomes following revisions and secondary implantation of the artificial urinary sphincter. J Urol 2005;173:1242-1245.

-22 Lai HH, Hsu EI, Teh BS, Butler EB, Boone TB: 13 years of experience with artificial urinary sphincter implantation at Baylor College of Medicine. J Urol 2007;177:1021-1025. 